\title{
A participação do pai no Aleitamento Materno: Uma rede de apoio
}

\author{
Father's participation in Breastfeeding: A network of support \\ Participación del padre en la Lactancia: Una red de apoyo
}

Recebido: 04/01/2022 | Revisado: 16/01/2022 | Aceito: 20/01/2022 | Publicado: 22/01/2022

\author{
Jessica Assumpção de Oliveira \\ ORCID: https://orcid.org/0000-0002-4993-3763 \\ Centro Universitário IBMR Barra, Brasil \\ E-mail: jessicaoliveira2000@yahoo.com.br \\ Luciana Rosa e Silva Cardoso \\ ORCID: https://orcid.org/0000-0002-9434-233X \\ Centro Universitário IBMR Barra, Brasil \\ E-mail: lunutricao16@gmail.com \\ Roberta de Oliveira Manhães da Silva \\ ORCID: https://orcid.org/0000-0001-5390-9793 \\ Centro Universitário IBMR Barra, Brasil \\ E-mail: roberta-manhaes@hotmail.com \\ Veronica Nunes da Silva Cardoso \\ ORCID: https://orcid.org/0000-0003-2651-3632 \\ Centro Universitário IBMR Barra, Brasil \\ E-mail: veronica.cardoso@ibmr.br
}

\begin{abstract}
Resumo
Objetivou-se analisar de acordo com a literatura sobre a importância do apoio paterno no aleitamento materno. Tratase de uma revisão integrativa, realizada de março a junho de 2020. Utilizou-se os descritores paternidade, aleitamento materno, enfermagem e saúde da mulher, nas bases: SciELO, LILACS, BDENF. Encontraram-se 7 artigos, dos quais, observou-se que a presença do pai no aleitamento materno exclusivo, além de fortalecer o vínculo familiar, ressalta sua importância no processo, os profissionais da saúde são de suma importância nesse processo, por manter a aderência, cuidados, orientações e ampliar a rede de apoio. Evidenciou-se que o pai tem grande influência no aleitamento materno, pois sem essa ajuda se torna difícil o processo de amamentar e a aderência da mãe, visto todas as dificuldades. Sugerese o planejamento de estratégias pelas equipes de saúde que podem orientar e estimular a participação efetiva do pai na realização do apoio a mulher no aleitamento materno.
\end{abstract}

Palavras-chave: Aleitamento materno; Paternidade; Enfermagem; Saúde da mulher.

\begin{abstract}
The objective was to analyze, according to the literature, the importance of paternal support in breastfeeding. This is an integrative review, carried out from March to June 2020. The descriptors paternity, breastfeeding, nursing and women's health were used, based on: SciELO, LILACS, BDENF. There were 7 articles, of which, it was observed that the presence of the father in exclusive breastfeeding, in addition to strengthening the family bond, highlights its importance in the process, health professionals are of paramount importance in this process, for maintaining adherence, care, guidance and expanding the support network. It was evidenced that the father has a great influence on breastfeeding, because without this help the breastfeeding process and the mother's adherence become difficult, given all the difficulties. It is suggested that health teams plan strategies that can guide and encourage the effective participation of the father in providing support to women in breastfeeding.
\end{abstract}

Keywords: Breastfeeding; Paternity; Nursing; Women's health.

\section{Resumen}

El objetivo fue analizar, según la literatura, la importancia del apoyo paterno en la lactancia materna. Esta es una revisión integradora, realizada de marzo a junio de 2020. Se utilizaron los descriptores de paternidad, lactancia, enfermería y salud de la mujer, basados en: SciELO, LILACS, BDENF. Hubo 7 artículos, de los cuales, se observó que la presencia del padre en la lactancia materna exclusiva, además de fortalecer el vínculo familiar, destaca su importancia en el proceso, los profesionales de la salud son de suma importancia en este proceso, para mantener la adherencia, atención, orientación y ampliación de la red de apoyo. Se evidenció que el padre tiene una gran influencia en la lactancia materna, porque sin esta ayuda se hace difícil el proceso de lactancia materna y la adhesión de la madre, dadas todas las dificultades. Se sugiere que los equipos de salud planifiquen estrategias que puedan guiar y alentar la participación efectiva del padre para brindar apoyo a las mujeres en la lactancia materna.

Palabras clave: Amamantamiento; Paternidad; Enfermería; La salud de la mujer. 


\section{Introdução}

O aleitamento materno é o alimento essencial para bebês de até seis meses de vida e, após esse período, deve ser oferecido até os dois anos de idade ou mais, como preconiza a OMS (Organização Mundial de Saúde), porque evita a mortalidade infantil, infecção respiratória, diminui o risco de alergias, hipertensão, colesterol alto e diabetes, obesidade, e há uma melhor nutrição, pois, o leite materno é rico em nutrientes que ajudam no crescimento e desenvolvimento mental e físico da criança. $\mathrm{E}$ há benefícios para a mãe também como: acelerar a involução uterina pós-parto, reduzir a probabilidade de câncer de mama e ovário e também de desenvolver diabetes. Além de não ter custo e estar sempre à disposição do bebê e gerar um vínculo entre mãe e filho, já que proporciona conforto e aconchego (Teston et al., 2018).

Ao longo do século XX, houve uma diminuição da amamentação ocasionado pelo crescente aumento da colocação da mulher no mercado de trabalho, a produção do leite industrializado, as más práticas adotadas pelas maternidades e a falta de conhecimento da população sobre os benefícios do aleitamento materno, o que ocasionou em altos índices de mortalidade infantil. Com isso, na década de 80, a OMS intensificou as campanhas de promoção e apoio do aleitamento materno, o que contribuiu de forma positiva para o engajamento da campanha. $\mathrm{O}$ índice de amamentação exclusiva para menores de seis meses de idade, deveria ser de 50\% até 2025, conforme estabelecido pela Assembleia Mundial de Saúde, porém encontra-se aquém do sugerido na maioria dos países (Ferraz et al., 2016).

Foi criado no Brasil, o Programa Nacional de Incentivo ao Aleitamento Materno (PNIAM) visando a promoção, proteção e apoio do aleitamento materno. O PNIAM propôs o início da amamentação logo após o nascimento, a implantação do alojamento conjunto e não ofertar água e leite artificial nas maternidades. Portanto, a equipe de Enfermagem tem responsabilidade em colocar em prática essas condutas e informar os pais sobre a importância e continuidade do aleitamento materno (Brasil, 2017a).

Factualmente, o homem era responsável por ser o provedor financeiro enquanto a mulher cuidava dos filhos. De uns anos para cá, essa situação está mudando com políticas públicas de saúde que reforçam a importância da presença do pai no ciclo gravídico-puerperal, como por exemplo, o Movimento pela Valorização da Paternidade, criada pela Secretaria Municipal de Saúde e Defesa Civil do Rio de Janeiro (SMSDC/RJ),que tem como finalidade fazer com que o homem sinta-se valorizado e respeitado em seu paternar e receba orientações dos profissionais de saúde em relação às principais questões, como é o caso do aleitamento materno, que está ligado a questões sociais, econômicas e culturais. Portanto, o meio onde a mulher está inserida está diretamente ligado à continuidade no processo. Somente o desejo por amamentar não garante o sucesso na amamentação. É necessária e importante a presença do pai da criança dando apoio constante a mulher (Nascimento et al., 2019).

A sociedade impõe uma cultura onde o homem não faz parte do processo de aleitamento materno, gerando desta forma, um distanciamento dele nesse momento tão importante para mãe e bebê. Os pais sentem-se excluídos desse momento e por insegurança podem acabar desestimulando suas parceiras nesse processo. Por isso, é considerável a presença dos homens nas consultas pré-natais, ouvindo das enfermeiras sobre a importância do aleitamento materno e seus benefícios, para que sejam estimulados desde a gestação sobre os cuidados necessários para mãe e bebê. As enfermeiras têm papel fundamental no que diz respeito à promoção, proteção e incentivo à amamentação (Ferraz et al., 2016, Silva et al., 2019a).

Para que a nutrição do bebê seja feita pelo aleitamento materno exclusivo (AME) por um período prolongado é necessário que o pai colabore ajudando a mulher com as tarefas domésticas, ficando com o bebê enquanto a mãe descansa, e oferecendo apoio emocional, principalmente durante o puerpério, onde a puérpera pode desenvolver depressão pós-parto e, consequentemente, interromper o aleitamento. A fim de que haja esse suporte do homem é valoroso que ele esteja presente nas consultas pré-natais, roda de gestantes, sala de parto para entender a importância dessa parceria e colaborar no incentivo à amamentação, evitando o desmame precoce. Pois, assim como é uma mudança de vida para a mãe, é para o pai também que se vê apreensivo, medroso, responsável por um novo ser e se adaptando à uma nova vida conjugal (Silva et al., 2012). 
A participação e compreensão do pai na assistência à mulher nos primeiros dias de aleitamento materno é considerável e tem consequência na duração da amamentação, pois é importante que ele esteja ao lado da puérpera caso haja algum evento adverso, como por exemplo, fissura mamária, mastite, ingurgitamento mamário, pega incorreta do bebê. Em todas essas situações, o pai tem responsabilidade pela manutenção do aleitamento materno, seja dando apoio moral e emocional à mulher, seja ajudando-a a corrigir a posição do bebê e realizando a ordenha. Em muitos casos, o homem não participa e sugere que a mulher ofereça fórmula para o bebê, através da mamadeira, e chupeta, o que estudos já comprovam que bicos artificiais prejudicam a continuidade do aleitamento materno (Silva et al., 2012).

É importante salientar que a participação ativa do pai ajuda na produção e ejeção do leite, atuando assim os hormônios da prolactina e ocitocina. Pois dessa forma, diminui as chances da mulher ficar sobrecarregada, estressada e, mantendo a saúde mental boa, ela consegue ter calma e paciência para amamentar o bebê por um período prolongado (Silva et al., 2019a).

O estudo releva-se no entendimento de que a participação paterna auxilia no puerpério diante do apoio psicológico, bem como no metabólico ao bom seguimento do aleitamento materno, justificando-se na identificação da rede de apoio como facilitação na adesão ao aleitamento materno e contribuindo para o ensino e conscientização, de forma com que seja possível reforçar a importância do apoio paterno a mulher no aleitamento materno, para a pesquisa um aumento sobre a abordagem desse tema e para a assistência.

Sendo assim, objetivou-se analisar de acordo com a literatura sobre a importância do apoio paterno no aleitamento materno.

\section{Metodologia}

Trata-se de uma revisão integrativa de literatura, de aspecto descritivo, com abordagens qualitativas. Delimitando-se as seguintes etapas: identificação do tema ou questionamento da revisão integrativa; estabelecimento de critérios para inclusão e exclusão de estudos/ amostragem ou busca na literatura; definição das informações a serem extraídas dos estudos selecionados/ categorização dos estudos; avaliação dos estudos incluídos na revisão integrativa; interpretação dos resultados; apresentação da revisão/ síntese do conhecimento (Mendes et al., 2008).

Estabeleceu-se a seguinte pergunta da pesquisa: "De acordo com a literatura nos últimos 5 anos, como está representada a participação paterna diante do acompanhamento ao aleitamento materno?". Para obtenção da resposta, utilizou-se a terminologia em saúde consultada nos Descritores em Ciências da Saúde (Decs), pelos quais identificaram-se os respectivos descritores: paternidade e aleitamento materno, em associação Operador Booleano "AND".

Os critérios de inclusão utilizados pelo estudo foram: a publicação apresentar como temática o pai no aleitamento materno; a participação paterna como rede de apoio ao aleitamento materno objeto de estudo; estar disponível de forma eletrônica, gratuita e na íntegra; ser artigo original; estar em português; publicações completas com resumos disponíveis das bases de dados: Scientific Eletronic Library Online (SciELO), Literatura Latino-Americana do Caribe em Ciências da Saúde (LILACS), Banco de Dados em Enfermagem (BDENF). Foram excluídos relatos de experiência, publicações duplicadas, editoriais, estudos reflexivos, cartas ao editor e estudos que não abordassem temática relevante ao objetivo da revisão.

$\mathrm{Na}$ base de dados LILACS, no cruzamento dos descritores foi empregado o operador booleano "AND" e utilizando a filtragem dos descritores paternidade e aleitamento materno, foram encontrados 73 artigos, após realizar a filtragem para artigos em português, texto completo, análise de títulos, resumos e o intervalo de anos proposto foram selecionados 5 artigos, 1 era inacessível e 2 obtinham os mesmos autores e somente de diferente era o artigo a no começo do título, ficando assim apenas 1 deles. Totalizando 3 artigos.

$\mathrm{Na}$ base de dados SciELO, no cruzamento dos descritores foi empregado o operador booleano "AND" e utilizando a filtragem dos descritores paternidade e aleitamento materno, foram encontrados 4 artigos, fazendo uma análise completa da 
leitura dos títulos, resumos e do intervalo de anos propostos pela pesquisa, foi selecionado 1 artigos.

$\mathrm{Na}$ base de dados BDENF, no cruzamento dos descritores foi empregado o operador booleano "AND” e utilizando a filtragem dos descritores paternidade e aleitamento materno, foram encontrados 9 artigos, fazendo uma análise completa da leitura de títulos, resumos e do intervalo proposto, foi selecionado 4 artigos, sendo que 2 obtinham os mesmos autores e somente de diferente era o artigo a no começo do título, ficando assim apenas 1 deles. Totalizando 3 artigos.

Para selecionar as publicações, leu-se minuciosamente cada título e resumo para confirmar se eles estavam de acordo com a pergunta norteadora desta investigação e se atenderiam aos critérios de inclusão e exclusão estabelecidos.

Para o registro e organização das informações dos estudos selecionados, foi elaborado um instrumento contendo: título, idioma, base de dados, ano e país de publicação.

Figura 1. Fluxograma da revisão.

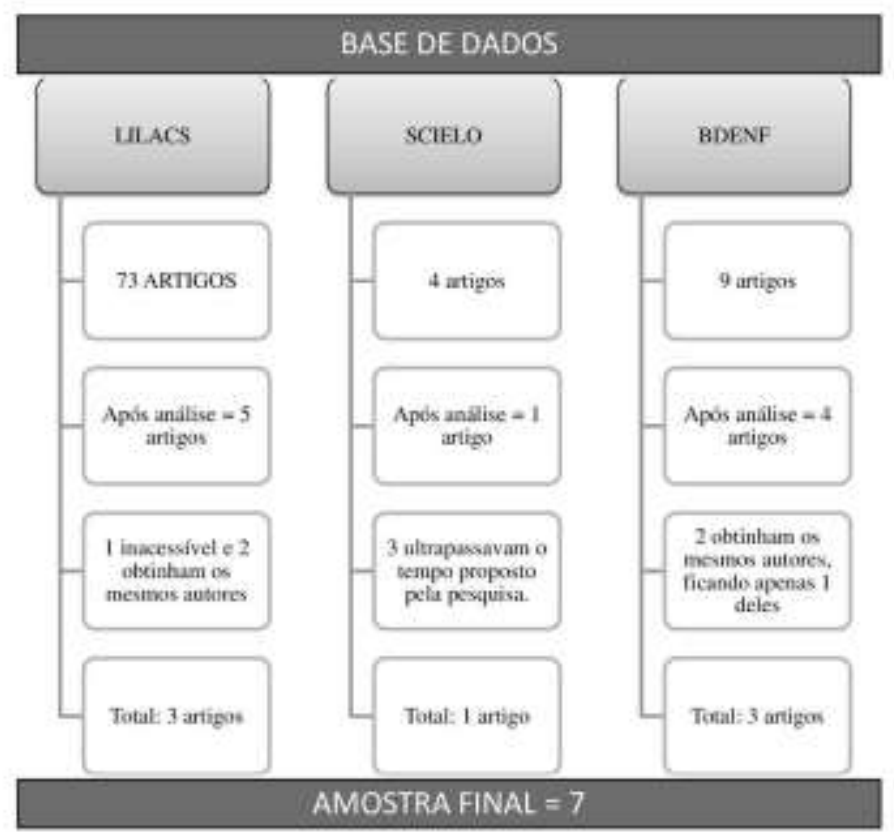

Fonte: Autores.

\section{Resultados}

A amostra desta revisão foi constituída pela totalidade de 7 artigos científicos, selecionados pelos critérios e inclusão estabelecidos, ressaltando a escassez de artigos nesse tema. Em relação à participação do pai no processo de aleitamento materno, uma pequena porcentagem de puérperas não considera essa participação importante, mas para a grande maioria a participação do pai nesse período é de extrema importância, inclusive as mães acham que, sem essa ajuda/participação seria muito difícil amamentar.

No Quadro 1, apresenta-se um panorama geral das publicações selecionadas para o estudo, destacando o periódico, autores, ano, título, metodologia e resultados. 
Quadro 1: Caracterização dos estudos utilizados.

\begin{tabular}{|c|c|c|c|c|c|}
\hline $\mathbf{N}^{\circ}$ & Periódico & Autores e Ano & Título & Metodologia & Resultados \\
\hline 1 & $\begin{array}{ll}\text { Revista } & \text { de } \\
\text { enfermagem } & \text { do } \\
\text { centro-oeste } & \\
\text { mineiro } & \\
\end{array}$ & $\begin{array}{l}\text { Teston, E.F., et } \\
\text { al., } 2018 .\end{array}$ & $\begin{array}{l}\text { Aleitamento materno: } \\
\text { percepção do pai sobre } \\
\text { seu papel. }\end{array}$ & $\begin{array}{l}\text { Pesquisa descritiva, de } \\
\text { natureza qualitativa. }\end{array}$ & $\begin{array}{l}\text { O envolvimento paterno no processo de aleitamento } \\
\text { materno constitui estratégia essencial para o } \\
\text { enfrentamento das dificuldades vivenciadas e para a } \\
\text { manutenção dessa prática. }\end{array}$ \\
\hline 2 & $\begin{array}{l}\text { Journal of } \\
\text { Nursing and } \\
\text { Health. }\end{array}$ & $\begin{array}{l}\text { Pinto, K.R.T.F., } \\
\text { et al., } 2018 .\end{array}$ & $\begin{array}{l}\text { Dificuldades na } \\
\text { amamentação: } \\
\text { sentimentos e percepções } \\
\text { paternas. }\end{array}$ & Estudo qualitativo & $\begin{array}{l}\text { Os pais tinham interesse em participar e apoiar suas } \\
\text { companheiras, porém não inseridos e estimulados pela } \\
\text { equipe de saúde. Expressaram sentimentos de } \\
\text { preocupação e tristeza diante das dificuldades, e estas } \\
\text { quando superadas o sentimento foi de alivio. }\end{array}$ \\
\hline 3 & $\begin{array}{l}\text { Revista } \\
\text { enfermagem } \\
\text { UERJ }\end{array}$ & $\begin{array}{l}\text { Fazio, I.A., et } \\
\text { al., } 2018 .\end{array}$ & $\begin{array}{lr}\text { Alimentação } & \text { e } \\
\text { aleitamento } & \text { materno } \\
\text { exclusivo do recém- } \\
\text { nascido: representação } \\
\text { social do pai. }\end{array}$ & $\begin{array}{l}\text { Estudo qualitativo, } \\
\text { fundamentado na } \\
\text { teoria das } \\
\text { representações sociais. }\end{array}$ & $\begin{array}{l}\text { A representação dos pais teve como influência os } \\
\text { significados de práticas culturais, todavia eles } \\
\text { reconhecem o aleitamento materno além do aspecto } \\
\text { nutricional, ou seja, valorizam a esfera afetiva dessa } \\
\text { prática. }\end{array}$ \\
\hline 4 & $\begin{array}{l}\text { Revista Médica } \\
\text { de Minas Gerais }\end{array}$ & $\begin{array}{l}\text { Silveira, F.J.F., } \\
\text { Barbosa, J.C. \& } \\
\text { Vieira, V.A.M., } \\
2018 .\end{array}$ & $\begin{array}{l}\text { Conhecimento dos pais } \\
\text { sobre o processo de } \\
\text { aleitamento materno em } \\
\text { mães de uma } \\
\text { maternidade pública em } \\
\text { Belo Horizonte, MG. }\end{array}$ & $\begin{array}{lr}\text { Estudo do } & \text { tipo } \\
\text { observacional } & \text { e } \\
\text { transversal. }\end{array}$ & $\begin{array}{l}\text { O pai, apesar de reconhecer a importância do } \\
\text { aleitamento materno, muitas vezes não conversa sobre } \\
\text { esse assunto com a mãe. A assistência educativa sobre } \\
\text { o aleitamento materno, por profissionais de saúde deve } \\
\text { incluir e motivar o papel do pai a participar ativamente } \\
\text { da amamentação. }\end{array}$ \\
\hline 5 & $\begin{array}{l}\text { Portal de revistas } \\
\text { de enfermagem }\end{array}$ & $\begin{array}{l}\text { Lima, J.P., } \\
\text { Cazola, L.H.O. } \\
\text { \& Picoli, R.P., } \\
2017 .\end{array}$ & $\begin{array}{l}\text { A participação do pai no } \\
\text { processo de } \\
\text { amamentação. }\end{array}$ & $\begin{array}{l}\text { Pesquisa descritiva de } \\
\text { abordagem } \\
\text { quantitativa. }\end{array}$ & $\begin{array}{l}\text { Estar junto da mulher é a maneira que os pais } \\
\text { encontraram para favorecer a amamentação e sua } \\
\text { participação é fundamental para o sucesso desse } \\
\text { processo. }\end{array}$ \\
\hline 6 & $\begin{array}{l}\text { Acta Paulista de } \\
\text { enfermagem }\end{array}$ & $\begin{array}{l}\text { Rêgo, R.M.V., } \\
\text { et al., } 2016\end{array}$ & $\begin{array}{l}\text { Paternidade } \\
\text { amamentação: mediação } \\
\text { da enfermeira }\end{array}$ & Estudo qualitativo. & $\begin{array}{l}\text { Evidenciou-se que pais demonstram satisfação em } \\
\text { prestar cuidados aos filhos e apoiar a amamentação } \\
\text { para contentamento de suas companheiras. }\end{array}$ \\
\hline 7 & $\begin{array}{l}\text { Periódicos } \\
\text { eletrônicos } \\
\text { psicologia }\end{array}$ & $\begin{array}{l}\text { Cherer, E.Q., } \\
\text { Ferrari, A.G. \& } \\
\text { Piccinini, C.A., } \\
2016 .\end{array}$ & $\begin{array}{l}\text { A amamentação e o } \\
\text { desmame no processo de } \\
\text { tornar-se pai }\end{array}$ & $\begin{array}{l}\text { Um pai primíparo foi } \\
\text { entrevistado no } 6^{\circ} \text { e } 20^{\circ} \\
\text { mês de vida da filha. }\end{array}$ & $\begin{array}{l}\text { Os relatos sugerem que, no processo de tornar-se pai, } \\
\text { a amamentação e o desmame também ganham } \\
\text { destaque, pois a amamentação pode estar associada à } \\
\text { relação corporal mãe-bebê e às dificuldades } \\
\text { experiências pelo homem enquanto terceiro. }\end{array}$ \\
\hline
\end{tabular}

Fonte: Autores.

Embora a amamentação esteja associada a benefícios comprovados para a mãe e a criança, existem muitos fatores que influenciam na decisão da mãe em oferecer o leite materno. Dentre esses, destacam-se o apoio e incentivo do companheiro oriundo do reconhecimento da importância desse processo.

Segundo Pinto et al (2018), atualmente a participação do pai é vista pela mãe como algo importante e desejável porque alivia a sobrecarga que a amamentação acarreta. A postura do pai como parceiro na prática da amamentação parece ser determinante para o seu sucesso e para a satisfação do casal. Foi identificado nos artigos selecionados que a participação do pai no processo de aleitamento materno dá-se na forma de ajuda à mulher.

Da análise dos dados de natureza qualitativa, surgiram as seguintes categorias: a) Percepção do pai sobre aleitamento materno; e b) $\mathrm{O}$ apoio paterno como facilitador disto. A percepção do pai sobre aleitamento materno observou-se o reconhecimento dos pais com relação à importância do AME. A finalidade e o tempo de amamentação também foram claramente evidenciados, conforme retratam as falas retiradas de um artigo original a seguir: "É importante para o desenvolvimento dele, para a saúde" (Ferraz et al., 2016).

"Eu acho que é bom para a saúde do bebê porque previne várias doenças". "Porque é mais saudável o leite materno da mãe do que esses leites de lata". "Quanto mais tempo, melhor". "O certo é até uns dois anos" (Teston et al., 2018).

A presença do companheiro mostrou-se importante também como apoio para amenizar as dificuldades vivenciadas pela mulher durante a amamentação, principalmente no início, quando a mesma se sente insegura com a descida do leite, por exemplo ou quando ocorre fissura mamária, momento da pega (se está correta ou não), se ele está sendo alimentado entre outros fatores (Brasil, 2009).

Ao analisar a experiência do pai sob a perspectiva do Cuidado Centrado na Família, foi possível perceber que, há momentos e situações em que a paternidade representa um período de grande responsabilidade na vida do homem que, por vezes, 
sente-se pouco participativo durante o processo gravídico-puerperal, pelo fato de a gestação ser sentida fisiológica e anatomicamente somente pela mulher (Amaral et al., 2015).

Contudo, os pais demonstram satisfação em acompanhar e apoiar o aleitamento materno, pois esse processo representa uma experiência marcante pela vivência de estar junto da mulher e do filho e de acompanhar completamente o seu desenvolvimento (Teston et al., 2018).

Um fator importante evidenciado durante esse momento são as orientações e apoio dado pelo profissional de saúde, para ser mais específico o enfermeiro, pois são os que passam mais tempo ao lado da gestante/puérpera. Alguns pais destacam que, ao longo das consultas de pré-natal que acompanharam, não receberam nenhuma orientação sobre o aleitamento materno, fato esse apresentado nas falas abaixo: "Ninguém falou sobre o aleitamento nas consultas de pré-natal", "Não me lembro de terem orientado sobre o aleitamento" Os pais relataram também diversas dificuldades que surgiram na amamentação, ainda na maternidade: "Se esse leite descesse mais rápido, iria facilitar, porque ela dá o peito, a neném fica chorando, ela fica irritada e tem que dar complemento pra ela". "Ela está reclamando de dor na barriga, nenhuma posição para ela está boa, daí fica ruim para amamentar". "Ela fica nervosa porque ela põe no peito, aí ele está com a boca parada dormindo, ela diz que ele está mamando, mas com a boca sem mexer? Daí eu falo: Eu acho que não está! Aí ela me mandou sair de perto. Eu quero ter certeza que ele não está passando fome, porque ele não sabe falar ainda” (Brasil, 2005 \& Brasil, 2017b).

Nesse contexto, destaca-se a importância desse estímulo que é oportunizado desde as consultas de pré-natal, as quais devem envolver o casal, de modo que os profissionais realizem orientações sobre amamentação e se tornem um desejo compartilhado pela família (Pinto et al., 2018).

Além disso, Lima et al. (2017) descrevem em sua pesquisa que o pai anseia participar da vida do bebê para exercer sua função parental e de responsabilidade que legitima seu papel com o mais novo membro da família. Nesse cenário, os profissionais de saúde necessitam tornar-se referência de cuidado e apoio para a família a fim de auxiliá-los ao longo do tempo, é preciso, portanto, que os enfermeiros acolham o casal no momento de realização das orientações durante as consultas de pré-natal e utilizem-se de diferentes estratégias para ressaltar a importância do fortalecimento do vínculo familiar, a fim de que os desafios vivenciados, ao longo do processo de amamentação, sejam debelados em conjunto.

Sendo assim, fica claro que a partir do momento em que os profissionais participam desse momento a aderência ao AME, se torna evidente e eficaz, além dos cuidados, higiene, vínculo entre profissional e a família tornando uma ampla rede de apoio e mais confiança em realizar o procedimento de maneira correta, além do apoio emocional que a mãe recebe nesse momento especial e delicado (Brasil, 2012).

\section{Discussão}

Existe um interesse científico para pesquisar os fatores capazes de afetar a duração do AME e, assim, desenvolver ações para promoção e proteção. Um deles, fundamental, porém pouco pesquisado e pouco conteúdo na literatura, é a presença do pai apoiando a mãe durante a lactação e participando nas decisões, não impondo o que achar melhor e sim tomando decisões juntos e chegando a um consenso do que é melhor para o bebê, com orientação dos profissionais da saúde (Rêgo et al., 2016).

O estudo de Rêgo et al (2016) trouxe dados que ampliam o conhecimento a respeito dos fatores paternos associados à duração do AME, os quais permitem pensar em novas estratégias para auxiliar o implemento dos índices de aleitamento materno, principalmente, orientando-os desde o pré-natal, já introduzindo essa cultura e orientando da forma correta, para minimizar dúvidas e acabar interrompendo a AM.

Observa-se que o apoio paterno informado pelas mães foi bastante evidente na aderência de AME nos primeiros meses. O mesmo foi constatado em artigos, mediante relatos das mães que o fator mais significativo para a interrupção do AME, foi por influência dos pais, por acharem que não estão sendo bem alimentados (Mendes et al., 2019). 
A validação e ajuda paterna no aleitamento materno faz com que as mulheres se sintam mais confiantes e seguras para continuar com o mesmo, pois trata-se de um momento de muita vulnerabilidade, onde a mulher tem alterações no humor, privação do sono, e se não tiver cooperação do parceiro, o desmame precoce pode acontecer. $\mathrm{O}$ uso de mamadeira, chupeta e leite artificial também contribuem para uma menor duração do aleitamento materno (Mendes et al., 2019).

A paternidade traz uma responsabilidade e medo na vida dos homens, assim como para a mulher. É necessário adaptarse ao novo momento na vida do casal com um bebê. Por essa razão, a presença do pai durante o pré-natal e nas rodas de gestantes é de muita notoriedade para que desde a gestação ele tenha ciência, através das informações dadas pelas enfermeiras, da importância do aleitamento materno junto com a parceira (Silva et al., 2012).

Os profissionais de Enfermagem têm grande valor na promoção e proteção do aleitamento materno visto que, as informações e trocas de experiências recebidas pelos pais durante o pré-natal refletem de forma positiva na continuidade da amamentação exclusiva até os seis meses de idade (Silva et al., 2019b).

A apresentação do homem como somente provedor financeiro tem sido deixado de lado e ele mostra-se interessado no processo do aleitamento materno, a partir do momento que durante o pré-natal percebe sua importância para auxiliar a parceira no suporte que ela necessitará durante o puerpério e os meses subsequentes (Rêgo et al., 2016).

\section{Considerações Finais}

Conclui-se que o pai tem grande influência no aleitamento materno, pois sem essa ajuda se torna difícil o processo de amamentar. O estudo buscou informações que reforçam a ideia de que as mães reconhecem a importância do pai no processo de AME, seja como incentivadores, orientadores, ajudadores dessa prática ou pelos cuidados ao bebê, aos afazeres do lar, ou simplesmente pelo conhecimento sobre a importância do aleitamento, fato este que claramente influência na decisão de amamentar. Além disso, eles percebem a importância para evitar doenças e se sentem orgulhosos de fazer parte desse momento, visto que culturalmente falando é exclusivo para a mãe.

Sugere-se o planejamento de estratégias pelas equipes de saúde que podem orientar e estimular a participação efetiva do pai e da família na realização de diversas tarefas que propiciam o aleitamento materno. Entretanto, acredita-se que os resultados, aqui apresentados, contribuem para expandir a compreensão da percepção paterna quanto ao seu papel no apoio e incentivo ao aleitamento materno, e estimular os profissionais de saúde a fortalecerem sua própria inclusão nas ações de cuidado.

Como sugestões para trabalhos futuros, recomenda-se a realização de uma pesquisa de campo sobre a temática, com os pais, verificando quantos participam e apoiam esse processo e qual papel é ou pode ser desempenhado pelos mesmos dentro do dia a dia do casal. Além disso, percebeu-se uma necessidade de que os profissionais de saúde estejam alinhados às recomendações da OMS e, assim, poderão prestar uma assistência qualificada e baseada em evidências científicas.

Almeja-se que essa pesquisa contribua para que os profissionais de saúde criem estratégias para trazer o pai para o prénatal, para orientá-lo e estimulá-lo a participar de forma efetiva do processo de aleitamento materno.

\section{Referências}

Amaral, L. J. X., et al. (2015). Fatores que influenciam na interrupção do aleitamento materno exclusivo em nutrizes. Rev Gaúcha Enferm. 36 (esp): $127-34$.

Brasil. Ministério da Saúde. Secretaria de Atenção à Saúde. Departamento de Ações Programáticas Estratégicas. (2017a). Bases para a discussão da Política Nacional de Promoção, Proteção e Apoio ao Aleitamento Materno. Brasília-DF, 68 p.

Brasil. Ministério da Saúde. Secretaria de Atenção à Saúde. Departamento de Ações Programáticas Estratégicas (2017b). Atenção humanizada ao recém-nascido: Método Canguru: Manual técnico, (3a ed.), Brasília, 340 p.

Brasil. Ministério da Saúde. Secretaria de Atenção à Saúde. Departamento de Ações Programáticas Estratégicas. (2012). Atenção à saúde do recém-nascido: guia para os profissionais de saúde, (2a ed.), Brasília, $195 \mathrm{f}$. 
Brasil. Ministério da Saúde. Secretaria de Atenção à Saúde. Departamento de Atenção Básica. (2009). Saúde da criança: Nutrição Infantil - Aleitamento Materno e Alimentação Complementar, $112 \mathrm{f}$.

Brasil. Ministério da Saúde. Secretaria de Atenção à Saúde. Departamento de Ações Programáticas Estratégicas. (2005). Área Técnica de Saúde da Mulher. Prénatal e Puerpério: Atenção qualificada e humanizada-Manual técnico, 163 p.

Cherer, E. Q., Ferrari, A. G. \& Piccinini, C. A. (2016). A amamentação e o desmame no processo de tornar-se pai. Estilos da Clínica, 21 (1): $12-29$.

Fazio, I. A., et al. (2018). Alimentação e aleitamento materno exclusivo do recém-nascido: representação social do pai. Revista Enfermagem UERJ, 26.

Ferraz, L., et al. (2016). Opinião de mulheres sobre a participação do pai no aleitamento materno. Arquivos de Ciências da Saúde da UNIPAR, Umuarama, 20 (2): 95-99.

Lima, J. P., Cazola, L. H. O. \& Picoli, R. P. (2017). A participação do pai no processo de amamentação. Cogitare Enfermagem, 22 (1): 01-07.

Mendes, S.C., et al. (2019). Fatores relacionados com uma menor duração total do aleitamento materno. Ciência \& Saúde Coletiva, 24 (5): 1821-1829.

Mendes, K. D. S., Silveira, R. C. C. P. \& Galvão, C. M. (2008). Revisão Integrativa: Método de Pesquisa para a Incorporação de Evidências na Saúde e na Enfermagem. Texto \& Contexto - Enfermagem, 17 (4): 758-64.

Nascimento, A. O., et al. (2019). A Importância do Acompanhamento Paterno no Pós-Parto e o Exercício da Paternidade. Revista Online de Pesquisa Cuidado é Fundamental. 11, 475-480.

Pinto, K. R. T. F., et al. (2018). Dificuldades na amamentação: sentimentos e percepções paternas. Journal of Nursing Health, 8 (1).

Rêgo, R. M. V., et al. (2016). Paternidade e amamentação: mediação da enfermeira: mediação da enfermeira. Acta Paulista de Enfermagem. 9 (4): $374-380$.

Silva, J. L. P., et al. (2019a). Fatores associados ao aleitamento materno na primeira hora de vida em um hospital amigo da criança. Texto \& Contexto Enfermagem, 27 (4).

Silva, N. V. N., et al. (2019b). Tecnologias em saúde e suas contribuições para a promoção do aleitamento materno: Revisão Integrativa da Literatura. Ciência \& Saúde Coletiva, 24 (2): 589-602.

Silva, P. P. S., et al. (2012). The maternal perception on paternal support: influence on the duration of breastfeeding. Revista Paulista de Pediatria, 30 (3): $306-$ 13 .

Silveira, F. J. F., Barbosa, J. C. \& Vieira, V. A. M. (2018). Conhecimento dos pais sobre o processo de aleitamento materno em mães de uma maternidade pública em Belo Horizonte, MG. Revista Médica de Minas Gerais, 28.

Teston, E. F., et al. (2018). Aleitamento materno: percepção do pai sobre seu papel. Revista de Enfermagem do Centro Oeste Mineiro, 8. 